Research Article

\title{
Calculation of Bearing Capacity and Deformation of Composite Pile Foundation with Long and Short Piles in Loess Areas
}

\author{
Tianzhong Ma $\mathbb{D}$, Yanpeng Zhu, and Xiaohui Yang \\ School of Civil Engineering, Lanzhou University of Technology, Langongping Road 287\#, Lanzhou 730050, China \\ Correspondence should be addressed to Tianzhong Ma; matz0914@163.com
}

Received 18 May 2020; Revised 3 September 2020; Accepted 28 September 2020; Published 24 October 2020

Academic Editor: Castorina S. Vieira

Copyright (c) 2020 Tianzhong Ma et al. This is an open access article distributed under the Creative Commons Attribution License, which permits unrestricted use, distribution, and reproduction in any medium, provided the original work is properly cited.

In order to calculate the bearing capacity and settlement deformation of composite pile foundations with long and short piles in collapsible loess areas, the theoretical approximate solution was used to obtain the location of the neutral point of single piles. Additionally, based on the equation to calculate the bearing capacity of multielement composite foundations, a method considering the negative frictional resistance was proposed for calculating the bearing capacity of composite pile foundations with long and short piles. Based on the shear displacement method and the principle of deformation control, an equation to calculate the displacement and deformation of a composite pile foundation was presented. A model test with different operating conditions, i.e., a single pile, four piles, and eight piles, was designed to verify the proposed calculation methods. The results show that the location of the neutral point has a significant influence on the single-pile negative frictional resistance, and the neutral point ratio of the calculation meets the value range of the practical project. When the load at the top of the pile is relatively small, the experimental curve is consistent with the theoretical calculation curve, whereas when the load is comparatively large, the theoretically calculated displacement increase at the top of the pile is greater than the measured one. Under the premise that the theoretical calculation is in good agreement with the results, the theoretical value is larger than the actual value. And it contributes to strengthening engineering safety.

\section{Introduction}

With superior force transmission performance, pile foundations have good applicability in improving the bearing capacity of foundations and controlling the settlement deformation of buildings [1]. The stress performance of largediameter cast-in-place concrete pile is good, which leads to more and more common application in pile foundation [2]. According to the engineering practice in collapsible loess areas, especially in loess areas with thick layers of loess, the pile end must penetrate the collapsible loess layer in general cases based on the principle of safety design. In the selfweight collapsible loess sites, the pile end should penetrate the collapsible layer to be supported by the reliable rock and soil layer; in the nonself-weight collapsible loess sites, the pile end should also be supported by the noncollapsible loess layer with relatively high bearing capacity. From the viewpoint of safety and stability, it is beyond doubt that pile foundations (especially pile length control) should be strictly designed. Nevertheless, with a continually improved understanding of the effective treatment thickness of collapsible loess foundation [3], we found that the design principle requiring all engineering piles to penetrate the collapsible loess layer is conservative and safe. Therefore, apart from optimizing the pile length, another key issue that remains to be solved is the determination of new pile foundations that are suitable for collapsible loess as well as their design theories and calculation methods.

With deformation control as the design principle, a composite pile foundation with long and short piles $[4,5]$ was proposed as applicable in loess areas based on the analysis principle of settlement reducing piles. The design principle is that when there are two or more bearing layers in the foundation soil, all the long piles will be located in the deep bearing layer to control the settlement deformation of the buildings, whereas the short piles will be located in the 
shallow bearing layers to provide the bearing capacity. In recent years, there are many extensive studies on composite pile foundations with long and short piles [6]. Field tests were carried out by Gotmann and Sokolov [7], and the performance of an XCC composite foundation on the basis of the load-settlement curves, axial force and side friction distribution, pile-soil load-sharing, and pile-soil stress ratio was studied, which has certain guiding effect on the bearing capacity of composite pile. Ma et al. [8] systematically expounded the design concept of a composite pile foundation with long and short piles for the first time, introduced the steps to calculate its bearing capacity and settlement, and analyzed the selection of related design parameters. Ge et al. [9] discussed the calculation methods for the bearing capacity and settlement of a composite pile foundation with long and short piles in a soft soil area and conducted a comparative analysis of the measured and calculated settlement values. According to the three-dimensional finite element analysis of a pile foundation with all short piles, a pile foundation with all long piles, and a composite pile foundation with long and short piles. Yang et al. [10] found that the composite pile foundation not only reduced the amount of long piles used but also effectively controlled the overall settlement and differential settlement of the foundation. In terms of calculating the settlement deformation of long and short piles, Yang et al. [11] proposed a practical settlement calculation method for composite pile foundations with long and short piles and applied it to the analysis of the settlement of a high-rise residential building. Zhao et al. [12, 13] established a calculation model for the settlement of composite pile foundations with long and short piles based on the shear displacement method with certain simplifying assumptions. Hong Y et al [14] carried out a field study on the downdrag and dragload of two pairs of bored piles installed in consolidating ground. The result shows that the dragload in a floating pile can be one-third less than that in an end-bearing pile with similar geometries and embedded in the same consolidating ground. Ni et al. [15] studied the effect of scouring around the pile on the lateral capacity of the piles embedded in sandy soil by the method of numerical investigation. Li and Gong [16] presented a method for predicting the load carrying behavior of pile groups consisting of new and existing displacement piles by combining the load-transfer method and shear displacement method and explored the stiffness efficiency and the loadsettlement behavior of pile groups with different layouts of new and existing piles. Li et al. [17] presented a semianalytical approach to predict the time-dependent bearing performance of an axially loaded jacked pile in saturated clay strata and provided an incremental algorithm and a corresponding computational code to assess the time-dependent load-settlement response of a jacked pile. There currently are many studies on the bearing capacity of composite pile foundations with long and short piles, but few in-depth studies have been conducted on their applicability in collapsible loess areas, and almost no theoretical analysis can be found regarding the location of the neutral point and calculation of the reduction effect of the bearing capacity of negative frictional resistance. Feng et al. [18], based on the modified Burgers model, proposed the nonlinear viscoelastic pile shaft and base load-transfer $(\mathrm{t}-\mathrm{z})$ models. By these models, a nonlinear approach was presented to calculate the long-term settlement of a vertically loaded single pile and a pile group in layered soft soil.

The pile-soil interface behavior is of particular interest in pile surface where shaft friction of pile plays an important role in resisting the applied load $[19,20]$. The objective of this study was to develop the theoretical design and calculation method of a composite pile foundation with long and short piles in collapsible loess areas. The location of the neutral point was determined through theoretical analysis, a method considering the negative frictional resistance was proposed to calculate the bearing capacity of the composite pile foundation, and the corresponding equation to calculate the displacement deformation was presented. Next, the model test was carried out to verify the rationality and applicability of the proposed methods for calculating the bearing capacity and settlement deformation. This paper aims to provide reference for theoretical research and engineering practice concerning composite pile foundations with long and short piles in loess areas.

\section{Calculation of Bearing Capacity of Composite Pile Foundation with Long and Short Piles in Loess Areas}

2.1. Determination of Neutral Points of Composite Pile Foundation with Long and Short Piles. The bearing capacity of the pile foundation is mainly provided by the pile-side frictional resistance and the pile-end resistance. The direction and magnitude of the pile-side frictional resistance depend on the relative displacement change of the pile and the soil around the pile. If the collapsible loess collapses, its displacement is usually greater than the displacement of the pile, and the soil around the pile has negative frictional resistance toward the pile. The negative frictional resistance assumes an inhomogeneous distribution and variation along the length of the pile. When the displacement of the pile and the soil around the pile are equal, the corresponding frictional resistance at this point is zero. Along this point, the displacement of the pile begins to grow larger than that of the soil around the pile; thus, the soil around the pile provides upward positive frictional resistance for the pile, which improves the bearing capacity of the pile foundation. Therefore, this point is the demarcation point of positive and negative frictional resistance, i.e., the so-called neutral point of the pile foundation in the collapsible loess layer. Field testing is the most reliable method to determine the neutral point in engineering design, but since field tests are timeconsuming and costly, estimation methods are used more often in practical applications. The commonly used methods for estimating the neutral point include the empirical method, the Japanese specification-based approach, and the theoretical approximate solution [19]. Although the empirical method does not involve complex calculation, it does not take into account influencing factors such as the properties of the soil around the pile, the load around the 
pile, or the characteristics of the pile, which leads to a relatively big deviation between the calculated location of the neutral point and the actual result. The Japanese specification-based approach [21] considers the influence of factors such as the additional load around the pile, the load at the top of the pile, the properties of the soil in each layer, and the characteristics of the pile body on the negative frictional resistance. The calculation results are relatively close to the measured values, but there are many parameters, so the actual operability is comparatively poor. Combining the advantages of the empirical method and the Japanese specification-based approach, the theoretical approximate solution considers the impact of factors such as the additional load around the pile, the load at the top of the pile, the properties of the soil in each layer, and the characteristics of the pile body on how the negative frictional resistance changes along the pile body, and its calculation parameters are common and easy to obtain. Therefore, the calculated results are in good agreement with the actual negative frictional resistance. Hence, in this study, the neutral point of the composite pile foundation with long and short piles was determined based on the theoretical approximate solution. According to the theoretical approximate solution and the force balance conditions of the pile, the following equation was obtained:

$$
P_{\text {up }}+P_{\mathrm{g}}+P_{\mathrm{sn}}=P_{\mathrm{s}}+P_{\mathrm{dp}},
$$

where $P_{\text {up }}$ is the load at the top of the pile; $P_{\mathrm{g}}$ is the gravitational force of the pile body; $P_{\mathrm{sn}}$ denotes the single-pile negative frictional resistance; $P_{s}$ is the positive frictional resistance; $P_{\mathrm{dp}}$ represents the pile-end resistance; and all variables are expressed in kilonewtons.

If the pile-side frictional resistance is assumed to be directly proportional to the effective pressure $q$ of the overlying soil, the $\beta$ method can be used to obtain the equation as follows:

$$
\begin{aligned}
P_{\mathrm{sn}} & =\int_{0}^{L_{f}} U_{\mathrm{p}} \beta_{1} \bar{q} \mathrm{~d} z=\int_{0}^{L_{f}} U_{\mathrm{p}} \beta_{1} \gamma^{\prime} z \mathrm{~d} z=\frac{1}{2} U_{\mathrm{p}} \beta_{1} \gamma L_{f}, \\
P_{\mathrm{s}} & =\int_{L_{f}}^{L} U_{\mathrm{p}} \beta_{2} \gamma^{\prime} \mathrm{d} z=\frac{1}{2} U_{\mathrm{p}} \gamma^{\prime} \beta_{2}\left(L^{2}-L_{f}^{2}\right),
\end{aligned}
$$

where $L$ is the length of the pile, with $m$ being the unit; $\gamma$ is the severity of the soil layer, and the floating severity will be used if it is below the groundwater level, with $\mathrm{kN} / \mathrm{m}^{3}$ being the unit; and $L_{\mathrm{f}}$ is the depth of the neutral point, with $m$ being the unit.

The pile-end resistance, $P_{\mathrm{dp}}$, was calculated according to the following equation:

$$
P_{\mathrm{dp}}=p_{\mathrm{dp}} A_{\mathrm{p}},
$$

where $P_{\mathrm{dp}}$ denotes the standard value of the extreme pile-end resistance, which can be valued according to the specification, and $A_{\mathrm{p}}$ is the pile-end area, with $\mathrm{m}^{2}$ being the unit. follows:

The $\beta$ coefficient was calculated based on the equation as

$$
\beta=0.18+0.0065 D_{\mathrm{r}},
$$

where $D_{\mathrm{r}}$ is the relative density.

Based on Equations (1)-(5), the following equation can be obtained:

$$
P_{\text {up }}+P_{\mathrm{g}}+\frac{1}{2} U_{\mathrm{p}} \beta \gamma L_{f}=\frac{1}{2} U_{\mathrm{p}} \gamma^{\prime} \beta\left(L^{2}-L_{f}^{2}\right)+p_{\mathrm{dp}} A_{\mathrm{p}} .
$$

By substituting different $P_{\text {up }}, \beta_{2}, \beta_{1}, P_{\mathrm{g}}, P_{\mathrm{dp}}$, and $A_{\mathrm{p}}$ into Equation (7), the location of the neutral point of each pile was obtained:

$$
L_{\mathrm{f}}=\frac{-U_{\mathrm{p}} \beta_{1} \gamma \pm \sqrt{\left(U_{\mathrm{p}} \beta \gamma\right)^{2}-8 \beta \gamma^{\prime} U_{\mathrm{p}} P_{\mathrm{up}}-8 U_{\mathrm{p}} P_{\mathrm{g}} \gamma^{\prime} \beta+4 U_{\mathrm{p}}^{2} \gamma^{2} \beta^{2} L^{2}+4 U_{\mathrm{p}} \gamma^{\prime} \beta P_{\mathrm{dp}} A_{\mathrm{p}}}}{2 U_{\mathrm{p}} \gamma^{\prime} \beta} .
$$

\subsection{Calculation of Pile-Group Negative Frictional Resistance of} Composite Pile Foundation with Long and Short Piles. In the previous section, the location of the neutral point of the pile and the single-pile negative frictional resistance were calculated based on the theoretical approximate solution; that is, the single-pile negative frictional resistance was calculated by simultaneously using Equations (7) and (2). The pilegroup negative frictional resistance of the composite pile foundation was determined by the following equation:

$$
Q_{g}^{\mathrm{n}}=\eta_{\mathrm{n}} \cdot \sum_{i=1}^{n} P_{\mathrm{sn}}
$$

where $Q_{g}^{\mathrm{n}}$ is the negative frictional resistance of the pile group, with $\mathrm{kN}$ being the unit; $n$ is the total number of piles; $\eta_{\mathrm{n}}$ is the pile-group effect coefficient of negative frictional resistance; and $P_{\text {sn }}$ denotes the single-pile negative frictional resistance, with $\mathrm{kN}$ being the unit.

In the above calculation of the pile-group negative frictional resistance, the pile-group effect of negative frictional resistance was considered. It is known that the pile-side negative frictional resistance was caused by the settlement deformation of the pile-side soil. If the weight of the soil shared by the surface of each pile in the pile group per unit area is less than the limit value of the single-pile negative frictional resistance, the negative frictional resistance of the foundation piles will decrease. Therefore, when calculating the negative frictional resistance of foundation piles in the pile group, the negative frictional resistance effect of the pile group should be taken into account. In this study, the pile-group effect coefficient of negative frictional resistance is represented by $\eta_{\mathrm{n}}$ and determined by the following equation: 


$$
\eta_{n}=\frac{s_{\mathrm{ax}} \cdot s_{\mathrm{ay}}}{\left[\pi d\left(\left(q_{s}^{n} / \gamma_{\mathrm{m}}\right)+(d / 4)\right)\right]}
$$

where $S_{\text {ax }}$ and $S_{\text {ay }}$ stand for the center distance of the vertical and horizontal piles, respectively, with $m$ being the unit; $d$ is the diameter of the pile, with $m$ being the unit; $\gamma_{\mathrm{m}}$ is the weighted average severity of the thickness of soil around the pile above the neutral point, with $\mathrm{kN} / \mathrm{m}^{3}$ being the unit; and $q_{\text {sn }}$ is the standard value of the weighted average negative frictional resistance of the thickness of soil around the pile above the neutral point, with $\mathrm{kN}$ being the unit.

\subsection{Calculation of Bearing Capacity of Composite Pile} Foundation with Long and Short Piles. Under normal circumstances, for site soil with special characteristics, a reinforcement body will be adopted to process the soil. If the control objectives of the bearing capacity or deformation still cannot meet the design requirements, it is stipulated in Recommendations for Design of Building Foundations [21] that a composite pile foundation with long and short piles can be used. Based on the area replacement rate and the pilesoil stress ratio, the bearing capacity of multielement composite foundations was obtained by summing the bearing capacities of the long piles, short piles, and the soil between the piles multiplied by corresponding effective strength coefficients. The bearing capacity of a multielement composite foundation, $f_{\mathrm{sp}, \mathrm{k} 2}$, can be calculated as follows:

$$
f_{\mathrm{sp}, \mathrm{k} 2}=m_{1} \frac{\lambda_{1} R_{\mathrm{k} 1}}{A_{1}}+m_{2} \frac{\lambda_{2} R_{\mathrm{k} 2}}{A_{2}}+\beta\left(1-m_{1}-m_{2}\right) f_{\mathrm{sk}},
$$

where $m_{1}$ and $m_{2}$ are the area replacement rates of short piles and long piles, respectively; $\lambda_{1}$ and $\lambda_{2}$ are the single-pile bearing capacity exertion coefficients of short piles and long piles, respectively; and $f_{\text {sk }}$ is the processed characteristic value of the bearing capacity of the soil between the piles of composite foundations, with $\mathrm{kPa}$ being the unit. The values of $\lambda_{1}$ and $\lambda_{2}$ should be determined by the single-pile composite foundation test according to equal deformation criteria or the static load test of the multipile composite foundation, and if there is regional experience, the value can be determined based on regional experience, while the value should be in the range of 0.7 to 0.9 if there is no regional experience.

In summary, the location of the neutral point and the negative frictional resistance were determined by the theoretical approximate solution. Equation (8), the equation to calculate the pile-group negative frictional resistance, was obtained based on Equation (2), the equation to compute the single-pile negative frictional resistance. According to Equation (10), which is the equation to calculate the bearing capacity of the soil between the piles of composite foundations, an equation that considers negative frictional resistance to calculate the bearing capacity of composite pile foundations with long and short piles in collapsible loess areas featuring thick layers of loess can be obtained as follows:

$$
f_{\mathrm{spk}}=m_{1} \frac{\lambda_{1} R_{\mathrm{k} 1}}{A_{1}}+m_{2} \frac{\lambda_{2} R_{\mathrm{k} 2}}{A_{2}}+\beta\left(1-m_{1}-m_{2}\right) f_{\mathrm{sk}}-Q_{g}^{\mathrm{n}} \text {, }
$$

where $f_{\text {spk }}$ is the bearing capacity of the composite pile foundation with long and short piles in a collapsible loess area, with $\mathrm{kN}$ being the unit.

According to the above analysis, Equation (11) solved the theoretical calculation of the bearing capacity of composite pile foundations with long and short piles in collapsible loess areas, thus providing a theoretical basis for the application of composite pile foundations with long and short piles in loess areas in Northwest China.

\section{Calculation of Settlement of Composite Pile Foundation with Long and Short Piles in Loess Areas}

Theoretically, in the calculation of the settlement deformation of multielement composite foundations, the composite foundation can be divided into the composite soil layer and the underlying soil layer. The common methods to calculate the settlement deformation of composite pile foundations with long and short piles include the composite modulus method, the stress correction method, and the shear displacement method. Among them, the composite modulus method recommended by Recommendations for Design of Building Foundations [21] ascertains the settlement of the foundation by calculating the composite modulus of the soil layer after long-short-piles treatment, but it requires a great number of moduli to be determined. Although the stress correction method is relatively simple, it is difficult to determine the pile-soil stress ratio and the stress correction coefficient of the composite foundation, and the role of long and short piles is ignored during the calculation process. According to the shear displacement method, Zhao et al. $[12,13]$ introduced a pile-pile and pile-soil interaction model based on specific assumptions. With the effect of the bedding layer considered, a method to calculate the settlement of a composite foundation was proposed based on the bedding-pile-soil joint action, but it did not take into account relevant problems caused by loess collapsibility.

Based on the principle of deformation control, Equation (11) was introduced to obtain a method that considers negative frictional resistance when calculating the settlement deformation of composite pile foundations in collapsible loess areas.

For simplification, Zhao et al. [12, 13] made the following assumptions: (1) both the soil layer between the piles of the composite foundation and the underlying layer are homogeneous elastomers, and the long and short piles share the same material and geometrical shape; (2) the foundation structure is absolutely rigid, and the vertical displacements under the raft are equal. The equation of the joint action of the pile-soil-raft system was obtained as follows:

$$
\{P\}=[K]\{w\},
$$


where $[K]$ is the stiffness matrix of the pile-soil-raft system, and $\{w\}$ and $\{P\}$ are the vertical displacement vector $\left\{w_{1}, w_{2}, \ldots, w_{i}, \ldots, w_{N}\right\}^{T}$ and the counterforce vector $\left\{P_{1}, P_{2}, \ldots, P_{i}, \ldots, P_{N}\right\}^{T}$, respectively, of relevant nodes.

The influences of the stiffness matrix of the pile-soil-raft system, the flexibility coefficients of pile-pile, pile-soil, and soil-soil interactions, and the raft action were considered. In the end, the basic form of the equation to calculate the settlement of the pile-soil-raft system was obtained as follows:

$$
w=\frac{\sum_{i=1}^{N} P_{i}}{\sum_{i=1}^{N} \sum_{j=1}^{N} k}=\frac{P}{\sum_{i=1}^{N} \sum_{j=1}^{N} k_{i j}},
$$

where $P$ is the total external load.

Equation (13) is an equation to calculate the settlement of composite foundations based on the shear displacement method proposed by Zhao Minghua and can be calculated by programming. However, the existence and impact of negative frictional resistance in the loess area were not considered. Therefore, based on the method for calculating the bearing capacity of composite foundations with long and short piles in collapsible loess areas proposed in this study, the following equation was obtained:

$$
f_{\text {spk }}=P \text {. }
$$

Therefore, with considering the pile-group negative frictional resistance, the method for calculating the settlement deformation of composite foundation with long and short piles in loess areas was established. The theoretical method to calculate the settlement of composite foundations with long and short piles based on deformation control was thereby presented.

\section{Indoor Verification Test}

To verify the proposed calculation method, a model test was carried out to verify the applicability and rationality of the theoretical algorithm.

4.1. Test Scheme. Three tests were designed: (1) the test of the bearing capacity of the foundation with a single pile; (2) the test of the bearing capacity of the foundation with 4 piles ( 2 short piles +2 long piles); and (3) the test of the bearing capacity of the foundation with 8 piles $(4$ short piles +4 long piles). Table 1 shows the test schemes of the composite pile foundations with long and short piles, and the layouts of the piles in the tests are shown in Figure 1.

\subsection{Test Model}

4.2.1. Pile-Bottom Spring. During this test, the spring was used to analyze the deformation characteristics of the soil at the bottom of the pile. The deformation parameters of the springs were measured by the universal testing machine, and the spring matched to the soil at the bottom of the pile was then selected. The rigidity coefficient of the spring selected for this test was $22.3 \mathrm{kN} / \mathrm{m}$, the length of the spring for the long pile was $0.1 \mathrm{~m}$, and the length of the spring for the short pile was $0.35 \mathrm{~m}$, as shown in Figure 2 .

4.2.2. Model Piles. A PVC pipe was used as a test pile to make a mold with an outer diameter of $75 \mathrm{~mm}$ and an inner diameter of $70 \mathrm{~mm}$. Four wires, each with a diameter of $4 \mathrm{~mm}$, were arranged around the PVC pipe and surrounded by a fine binding wire at an interval of $25 \mathrm{~mm}$ to form a wire cage with a diameter of $50 \mathrm{~mm}$. The wire worked as the longitudinal bar of the pile, and the fine binding wire was equivalent to the spiral stirrup. The pile was made of concrete with a strength grade of C25, as shown in Figure 3.

4.2.3. Screening and Filling of Soil around the Pile. The soil used in the test was Lanzhou collapsible loess. The water content of the soil was $12.98 \%$, and the maximum dry density $\rho_{\mathrm{d} \text {,max }}$ was $1.76 \mathrm{~kg} / \mathrm{m}^{3}$. The soil was then filled around the pile; the thickness of each layer of soil was $100 \mathrm{~mm}$, and the dropping height of each layer was kept the same. By testing the filling samples, it was found that the degree of compaction of the filled soil was $91 \%$, which satisfied the test requirements.

4.2.4. Loading. Currently, there are few experimental studies on this model pile. In this study, the bearing capacity of the model pile was estimated according to the Technical Code for Building Pile Foundations (JGJ94-2008) [22]. The loading amount of a single pile at each stage was assumed to be $0.5 \mathrm{kN}$, and the loading amount of a pile group at each stage was $n$ times that of a single pile at each stage, where $n$ is the number of piles in the pile group. Figure 4 shows the loading process.

\section{Results and Comparative Analysis}

5.1. Conversion between Single-Pile Settlement and Pile-Group Settlement. As experiment was set up using the test scheme described above, the length of the long piles was $1100 \mathrm{~mm}$, the length of the short piles was $850 \mathrm{~mm}$, and the piles were laid out in the shape of a plum blossom. The data measured by the model test can be used to find the relationship between the load at the top of the pile and the displacement of a single pile in a pile group, whereas Equation (13) is used to calculate the overall settlement of long and short piles, so it is necessary to convert the single-pile settlement into pilegroup settlement in the model test through reasonable calculation.

Considering the simplicity and practicability of the equivalent pier method [23] for calculating the settlement of a pile group based on the settlement of a single pile, the method was used to convert the settlement of the long and short piles obtained from the model test into the settlement of a pile group using the following equation:

$$
S=S_{\mathrm{st}}\left(\frac{d}{D_{\mathrm{eq}}}\right)^{-0.15},
$$


TABLE 1: Test schemes of composite pile foundations with long and short piles.

\begin{tabular}{lccccc}
\hline $\begin{array}{l}\text { Operating } \\
\text { conditions }\end{array}$ & $\begin{array}{c}\text { Number of } \\
\text { piles }\end{array}$ & $\begin{array}{c}\text { Number of } \\
\text { long piles }\end{array}$ & $\begin{array}{c}\text { Number of } \\
\text { short piles }\end{array}$ & $\begin{array}{c}\text { Number of long piles participating } \\
\text { in the operating conditions }\end{array}$ & $\begin{array}{c}\text { Number of short piles participating } \\
\text { in the operating conditions }\end{array}$ \\
\hline$(1)$ & 2 & 1 & 1 & 7 & 2 \\
$(2)$ & 4 & 2 & 2 & 4,10 & 5,9 \\
$(3)$ & 8 & 4 & 4 & $1,3,11,13$ & $2,6,8,12$ \\
\hline
\end{tabular}

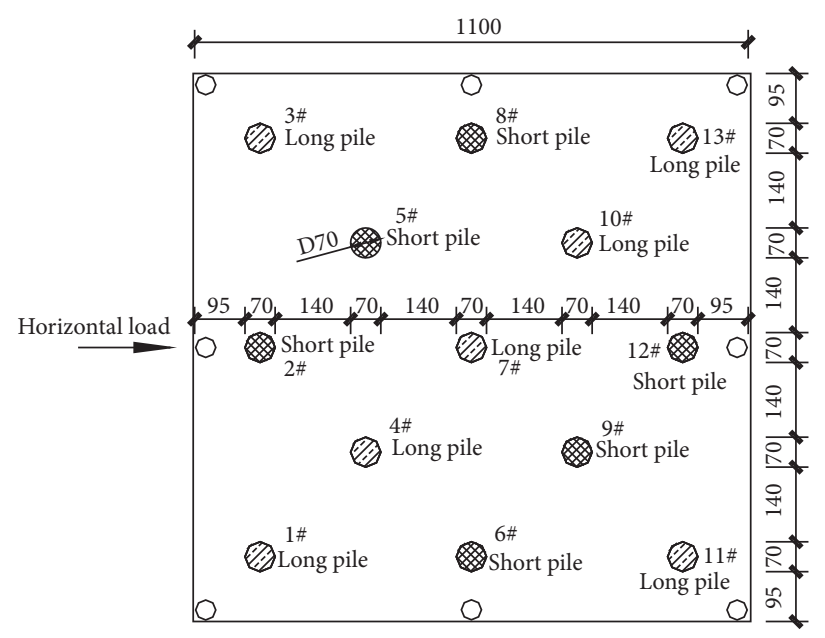

Figure 1: Layout of the piles in the test.

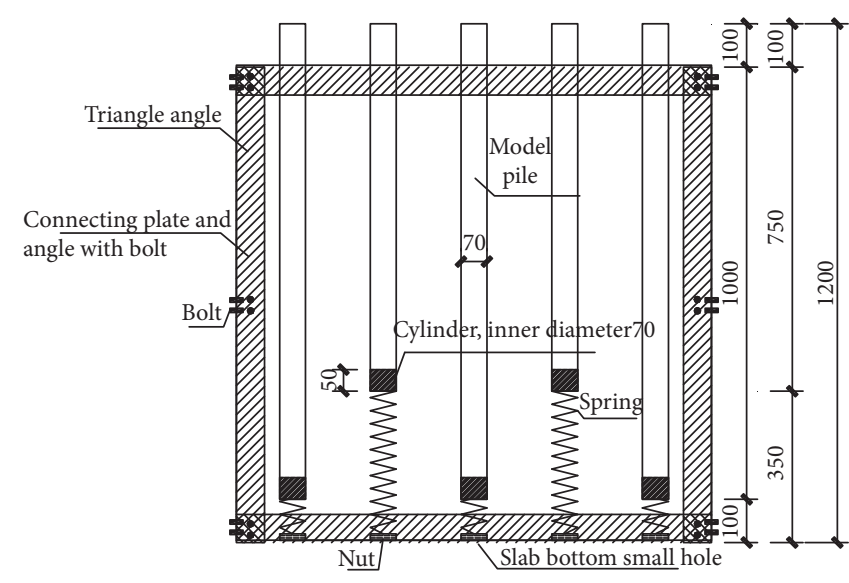

Figure 2: Vertical view of the test model.

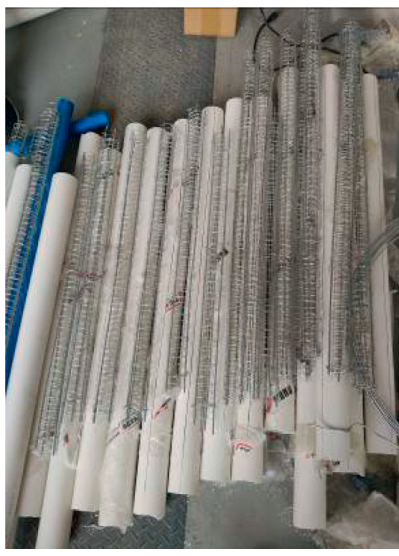

(a)

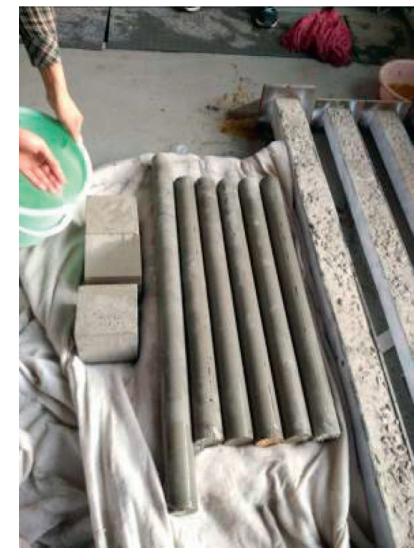

(b)

FIgUre 3: Physical diagrams of the model piles: (a) PVC pipe and wire cage; (b) maintenance model pile. 


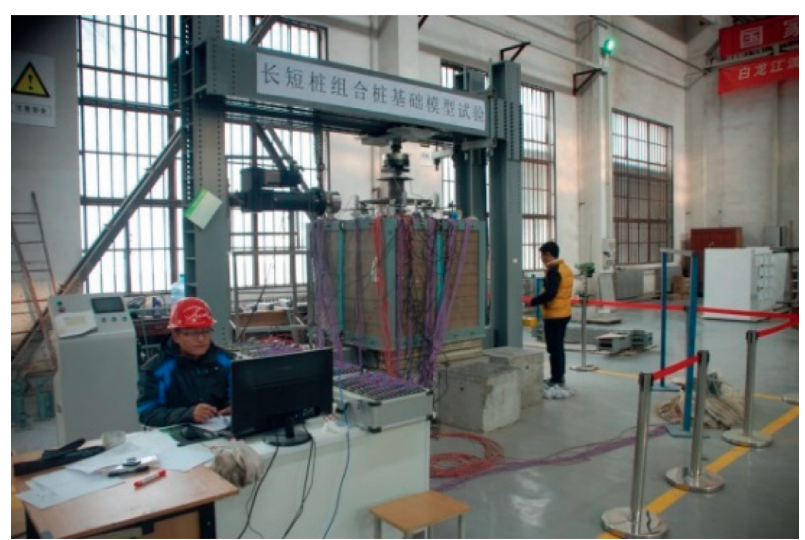

FIGURE 4: Loading process.

where $S$ is Winkel's ground coefficient and $S_{\text {st }}$ is the settlement of a single pile.

\subsection{Calculation of Neutral Point and Negative Frictional Resistance of Long and Short Piles}

5.2.1. Calculation of Neutral Point of Long and Short Piles. The neutral point of each long pile and short pile in this text was calculated based on Equation (7), and the results are shown in Table 2.

A large amount of experimental data has shown that the neutral point ratio is mostly between 0.35 and 0.70 [12]. The neutral point ratio calculated by Equation (7) in this test was within this range, indicating that the calculation result is reasonable.

5.2.2. Single-Pile Negative Frictional Resistance of Long and Short Piles. Due to the different locations of neutral points of long and short piles, the single-pile negative frictional resistance of long and short piles is inconsistent as well. The single-pile negative frictional resistance values of long and short piles were calculated by Equation (2), and the results are shown in Table 3.

It can be seen from Table 3 that the location of the neutral point had a significant influence on the single-pile negative frictional resistance. Due to the different locations of the neutral points of long and short piles, the negative frictional resistance of long piles was about 30\% larger than that of short piles.

5.2.3. Pile-Group Negative Frictional Resistance. For a pile group with relatively small pile spacing, the negative frictional resistance of foundation piles will be reduced due to the effect of the pile group. Equation (8) was used to calculate the negative frictional resistance of each pile group considering the pile-group effect coefficient of negative frictional resistance. The results are shown in Tables 4 and 5 .

According to the comparative analysis of Tables 4 and 5, since the composite foundation with 4 piles and the composite foundation with 8 piles had the same pile spacing and single-pile diameter, their pile-group effect coefficients were the same as well. Therefore, the difference between the negative frictional resistances of the two pile groups should be caused by the difference between the single-pile negative frictional resistances of long and short piles.

\subsection{Comparative Analysis of Model Test and Theoretical Calculation}

5.3.1. Analysis of the Test Results and Theoretical Calculation of Composite Foundation with 4 Piles. As shown in Figure 5(a), when the load at the top of the pile was less than $8 \mathrm{kN}$, the displacement at the top of the pile was relatively small, and the test curve was consistent with the theoretically calculated curve; both of which were around 0 to $0.4 \mathrm{~mm}$. When the load at the top of the pile exceeded $8 \mathrm{kN}$, the displacement at the top of the pile gradually increased and reached $1.5 \mathrm{~mm}$ when the load was $12 \mathrm{kN}$. When the load exceeded $12 \mathrm{kN}$, there were significant differences between the theoretical curve and the test curve. For the theoretically calculated curve, as the load at the top of the pile increased, the increase rate of the displacement at the top of the pile was larger than the corresponding part of the test curve. When the load at the top of the pile reached $16 \mathrm{kN}$, the actual settlement value was $8.5 \mathrm{~mm}$, whereas the theoretical settlement value was $10.5 \mathrm{~mm}$, which is about $23.5 \%$ larger than the actual settlement value. The reason may be that the theoretical calculation considered the negative frictional resistance of the pile group and the effect of pile caps brought by the collapsible layer, while the collapsible layer may not have completely collapsed and caused negative frictional resistance to the long and short piles in the test. In general, the theoretical value was larger than the actual value, which is conservative, and thus conducive to increased engineering safety.

5.3.2. Analysis of the Test Results and Theoretical Calculation of Composite Foundation with 8 Piles. Figure 5(b) compares the test curve and the theoretically calculated settlement curve of the composite foundation with 8 piles. When the load at the top of the pile was less than $9 \mathrm{kN}$, the measured and theoretically calculated settlement curves were basically the same. However, when the load at the top of the pile was greater than $14 \mathrm{kN}$, the measured and theoretical curves were significantly different. Similar to the results of the composite foundation with 4 piles, the theoretical settlement curve of the composite foundation with 8 piles was larger than the actual settlement curve. When the load at the top of the pile exceeded $21 \mathrm{kN}$, as the load at the top of the pile increased, the theoretically calculated displacement at the top of the pile increased rapidly. When the load at the top of the pile reached $32 \mathrm{kN}$, the theoretical settlement was $26.5 \mathrm{~mm}$, which is $26.03 \%$ higher than the actual settlement value of $19.6 \mathrm{~mm}$. The theoretical value was larger than the actual value, which is comparatively conservative, and therefore beneficial to engineering safety. 
TABLe 2: Neutral point $L_{f}$ of the long and short piles.

\begin{tabular}{lccccccc}
\hline Pile type & Diameter $(\mathrm{mm})$ & $\beta$ & $\gamma\left(\mathrm{kN} / \mathrm{m}^{3}\right)$ & $\mathrm{L}(\mathrm{m})$ & $P_{\mathrm{dp}}(\mathrm{kPa})$ & Neutral point ratio $\left(L_{n} / L_{o}\right)$ & $L_{f}(\mathrm{~mm})$ \\
\hline Long pile & 70 & 0.19 & 16 & 1100 & 2100 & 0.47 & 517 \\
Short pile & 70 & 0.19 & 16 & 850 & 2100 & 0.41 & 348.5 \\
\hline
\end{tabular}

TABLE 3: Single-pile negative frictional resistance $P_{\mathrm{sn}}$ of long and short piles.

\begin{tabular}{lccccc}
\hline Pile type & $U_{\mathrm{p}}(\mathrm{mm})$ & $\beta$ & $\Gamma\left(\mathrm{kN} / \mathrm{m}^{3}\right)$ & $L_{f}(\mathrm{~mm})$ & $P_{\text {sn }}(\mathrm{kN})$ \\
\hline Long pile & 219.8 & 0.19 & 16 & 517 & 0.17 \\
Short pile & 219.8 & 0.19 & 16 & 348.5 & 0.13 \\
\hline
\end{tabular}

TABle 4: Negative frictional resistance $Q_{g}^{n}$ of the pile group consisting of 4 piles.

\begin{tabular}{lccccc}
\hline $\begin{array}{l}\text { Number of long } \\
\text { piles }\end{array}$ & $\begin{array}{c}\text { Number of short } \\
\text { piles }\end{array}$ & $\begin{array}{c}\text { Single-pile negative frictional } \\
\text { resistance } \\
\text { of long piles }(\mathrm{kN})\end{array}$ & $\begin{array}{c}\text { Single-pile negative } \\
\text { frictional } \\
\text { resistance of short piles } \\
(\mathrm{kN})\end{array}$ & $\begin{array}{c}\text { Pile-group } \\
\text { effect } \\
\text { coefficient }\end{array}$ & $\begin{array}{c}\text { Pile-group negative } \\
\text { frictional resistance } \\
(\mathrm{kN})\end{array}$ \\
\hline 2 & 2 & 0.17 & 0.12 & 0.68 & 0.37 \\
\hline
\end{tabular}

TABle 5: Negative frictional resistance $Q_{g}^{n}$ of the pile group consisting of 8 piles.

\begin{tabular}{lccccc}
\hline $\begin{array}{l}\text { Number of long } \\
\text { piles }\end{array}$ & $\begin{array}{c}\text { Number of short } \\
\text { piles }\end{array}$ & $\begin{array}{c}\text { Single-pile negative frictional } \\
\text { resistance } \\
\text { of long piles }(\mathrm{kN})\end{array}$ & $\begin{array}{c}\text { Single-pile negative } \\
\text { frictional } \\
\text { resistance of short piles } \\
(\mathrm{kN})\end{array}$ & $\begin{array}{c}\text { Pile-group } \\
\text { effect } \\
\text { coefficient }\end{array}$ & $\begin{array}{c}\text { Pile-group negative } \\
\text { frictional resistance } \\
(\mathrm{kN})\end{array}$ \\
\hline 4 & 4 & 0.17 & 0.12 & 0.68 \\
\hline
\end{tabular}

Load on pile top $(\mathrm{kN})$

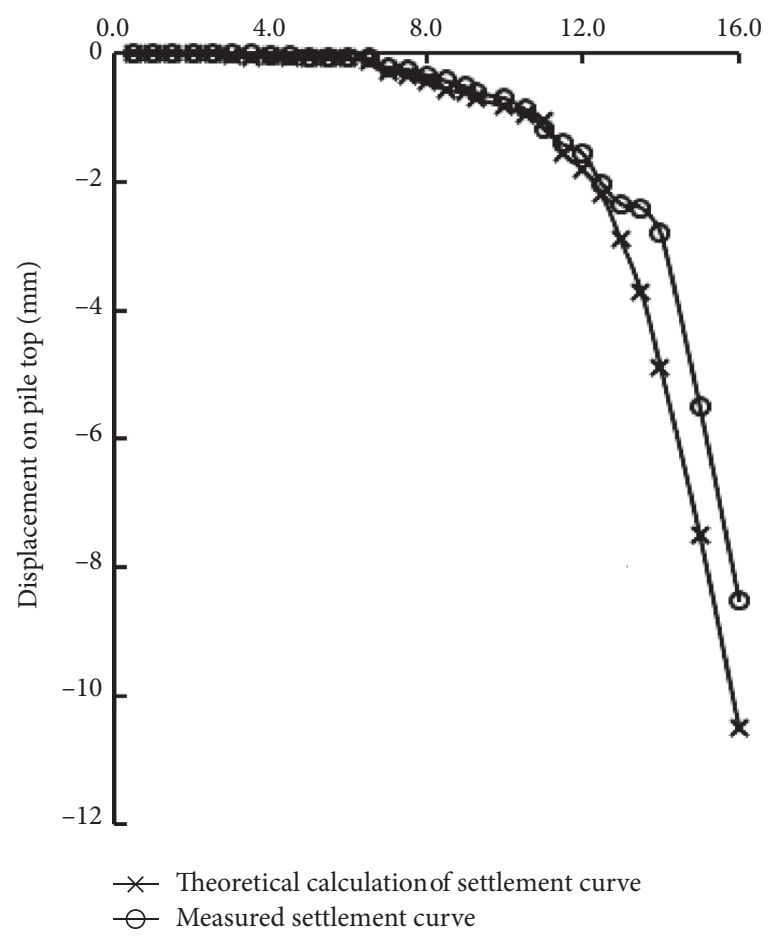

(a)
Load on pile top $(\mathrm{kN})$

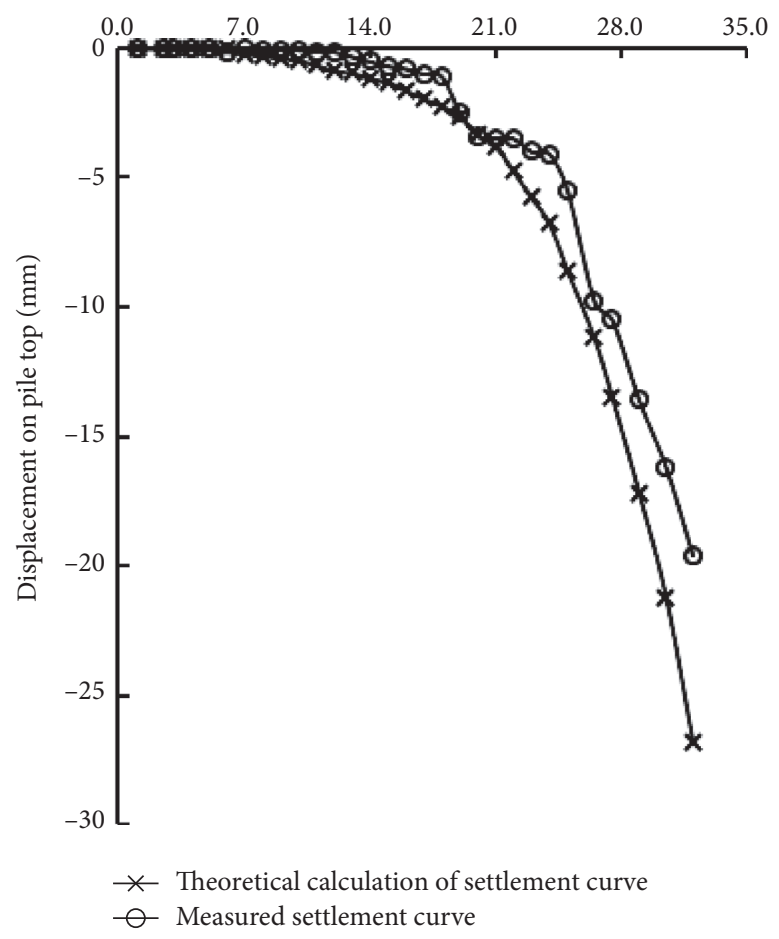

(b)

Figure 5: Comparison of the measured and the theoretically calculated settlement curves: (a) four piles; (b) eight piles. 


\section{Conclusions}

(1) In this study, the location of the neutral point of a single pile was obtained based on the theoretical approximate solution, and a method considering the negative frictional resistance was proposed to calculate the bearing capacity of composite pile foundations with long and short piles based on the equation to calculate the bearing capacity of multielement composite foundations recommended by the specification.

(2) With the shear displacement method as the theoretical basis to calculate the settlement deformation, the method for calculating the bearing capacity proposed in this study was used to replace its load calculation parameters so that the calculated results of the negative frictional resistance were internally included to present the method for calculating the settlement deformation of composite pile foundations with long and short piles.

(3) As indicated by the comparison between the indoor model test and the results calculated using the method proposed in this study, the calculated location of the neutral point is within the engineering practice experience in engineering practice. The comparison between the theoretically calculated settlement value and the settlement results obtained in the test shows that when the load at the top of the pile is relatively small, the displacement at the top of the pile is comparatively small as well, and the test curve is consistent with the theoretically calculated curve. When the load at the top of the pile is relatively large, the displacement at the top of the pile gradually increases, and there are differences between the theoretical curve and the measured curve; that is, the increased rate of the theoretically calculated displacement at the top of the pile is larger than that of the measured one.

(4) Through comparative analysis of the test and the theoretical calculation, it is found that the theory proposed in this study to calculate the bearing capacity and settlement deformation of composite pile foundations with long and short piles is relatively reasonable and it is applicable to foundation engineering in collapsible loess areas.

\section{Data Availability}

Some or all data, models, or code that support the findings of this study are available from the corresponding author upon reasonable requests including discussion with the authors, repeating the tests, and other situation.

\section{Conflicts of Interest}

The authors declare that there are no conflicts of interest regarding the publication of this paper.

\section{Acknowledgments}

This work was supported by the National Science Foundation of China "Basic Theory Analysis and Test Study on Long-Short Piles in Collapsible Loess Region with Big Thickness" (no. 52068048) and the Program for Changjiang Scholars and Innovative Research Team in University (no. IRT 17R51).

\section{References}

[1] J. Dong and X. Zhao, Foundation of High-Rise Buildings-Theory and Practice of Common Action, Tongji University Press, Shanghai, China, 1997.

[2] I. A. Bokov and V. G. Fedorovskii, "On the calculation of groups of piles using mutual influence coefficients in the elastic half-space model," Soil Mechanics and Foundation Engineering, vol. 54, no. 6, pp. 363-370, 2018.

[3] X. Yang, X. Huang, Y. Zhu et al., "Experimental study ON collapsibility evaluation and treatment depths OF collapsible loess UPON self weight with thick depth," Chinese Journal of Rock Mechanics and Engineering, vol. 33, no. 5, pp. 1063-1074, 2014.

[4] Y. Guo and T. Zhou, Theory and Engineering Application of Composite Pile Foundation with Rigid Long and Short Piles, Science Press, Beijing, China, 2015.

[5] X. Zhu, Yangmin, H. Yang et al., "Study on bearing behaviors and model tests of composite pile foundation with long and short piles," Chinese Journal of Geotechnical Engineering, vol. 29, no. 4, pp. 580-586, 2007.

[6] Z. Fan, Y. C. Zhang, and H. K. Liu, "Design and application of long-short-pile composite foundation," Advanced Materials Research, vol. 790, pp. 329-332, 2013.

[7] A. L. Gotman and L. Y. Sokolov, "Lateral load analysis of a composite pile," Soil Mechanics and) Foundation Engineering, vol. 55, no. 2, pp. 103-109, 2018.

[8] Y. Ma, D. Zhang, Z. Zhang et al., "Design of the composite foundation with long-short-pile," Geotechnical Engineering Technique, vol. 2, pp. 86-91, 2001.

[9] X. Ge, X. Gong, and X. Zhang, "FEM analysis and design of long short pile composite pile foundation," Building Structure, vol. 32, no. 7, pp. 3-5, 2002, in Chinese.

[10] M. Yang, H. Yang, and W. Wang, "Design philosophy and settlement analysis OF the composite long-short pile foundations," China Civil Engineering Journal, vol. 38, no. 12, pp. 103-108, 2005.

[11] J. Yang, X. Gong, and B. Sun, "Discussion on settlement calculation method for long-short-pile composite pile foundation," Building Structure, vol. 32, no. 7, pp. 8-10, 2002.

[12] M. Zhao, L. Zhang, and M. Yang, "Settlement calculation of the long-short-pile composite foundation with shear displacement method," Chinese Journal of Geotechnical Engineering, vol. 27, no. 9, pp. 994-998, 2005.

[13] M.-H. Zhao, L. Zhang, and M.-H. Yang, "Settlement calculation for long-short composite piled raft foundation," Journal of Central South University of Technology, vol. 13, no. 6, pp. 749-754, 2006.

[14] Y. Hong, C. W. W. Ng, Y. M. Chen et al., "Field study of downdrag and dragload of bored piles in consolidating ground," Journal of Performance of Constructed Facilities, vol. 30, no. 3, Article ID 04015050, 2016.

[15] S.-H. Ni, Y.-H. Huang, and K.-F. Lo, "Numerical investigation of the scouring effect on the lateral response of piles in sand," 
Journal of Performance of Constructed Facilities, vol. 26, no. 3, pp. 320-325, 2012.

[16] L. Li and W. Gong, "Prediction of nonlinear vertical settlement of a pile group consisting of new and existing displacement piles in clay strata," Soils and Foundations, vol. 59, no. 5, pp. 1336-1348, 2019.

[17] L. Li, L. Jingpei, S. De'an, and G. Weibing, "A semi-analytical approach for time-dependent load-settlement response of a jacked pile in clay strata," Canadian Geotechnical Journal, vol. 54, no. 12, pp. 1682-1692, 2017.

[18] S. Feng, X. Li, F. Jiang, L. Lei, and Z. Chen, "A nonlinear approach for time-dependent settlement analysis of a single pile and pile groups," Soil Mechanics and Foundation Engineering, vol. 54, no. 1, pp. 7-16, 2017.

[19] R. Nie, W. Leng, Q. Yang et al., "Effects of pile residual loads on skin friction and toe resistance," Soil Mechanics and Foundation Engineering, vol. 55, no. 2, pp. 76-81, 2018.

[20] X. Hu, X. Zhang, H. Liu et al., "Comparison and analysis of estimation methods for depth of neutral point of pile foundation," Chinese Journal of Geotechnical Engineering, vol. 33, no. 2, pp. 184-187, 2011.

[21] Architectural Institute of Japan, Recommendations for Design of building Foundations, Maruzen Publishing, Tokyo, Japan, 2001.

[22] JGJ94-2008, Technical Code for Building Pile Foundations, McGraw-Hill, New York, NY, USA, 2008.

[23] Q. Zhang and Z. Zhang, "A simplified calculation approach for settlement of pile groups," Rock and Soil Mechanics, vol. 33, no. 2, pp. 382-388, 2012. 